\title{
Liquid air for energy storage, auto-compression, compressed air and ventilation in deep mining
}

\author{
DL Cluff University of Exeter, UK \\ GA Kennedy University of Exeter, UK \\ PJ Foster University of Exeter, UK
}

\begin{abstract}
Deeper mining projects necessitate that ground control in high stress environments, ventilation and heat stress management be extended to the limit of current technologies; thus represent substantial research and development efforts to realise safe and profitable deep mining. In this paper, a concept is presented that serves to advance the potential for providing services and infrastructure for deep mining at potentially reduced costs. Liquid air (LA) is an energy storage vector that provides the opportunity for energy cost arbitrage through peak shaving or by smoothing the operation of wind turbines or solar power systems. By producing LA during operation of the wind turbines or during daylight hours and releasing the energy during low wind periods or evenings, the energy can be distributed more economically over time The infrastructure required for LA facilities is a reliable mature technology and competitive with competing energy storage systems.
\end{abstract}

As the mine depth increases, a LA energy storage system can deliver more than just energy storage, because a LA system may reduce the amount of some critical financial variables. For example, LA can deliver: chilling to offset auto-compression, improvements to ventilation on demand, rapid rock skin temperature conditioning, heat absorption at depth, arbitrage of electrical energy cost shifting, compressed air supply and operation of large vehicles. The Dearman engine uses $L A$ as a fuel, consequently when it is employed in trains, scoops and other equipment the exhaust of the large underground equipment becomes a source of cool air, which further reduces the ventilation required because dilution of diesel and removal of heat generated by equipment is no longer part of the ventilation calculation. LA can provide compressed air, routinely used to operate equipment or provide emergency ventilation. The losses in compressed air systems from long distance delivery and leaks en route, a common complaint of mine managers, are offset by using underground LA expansion; further absorbing heat and the proximal storage of the liquid air source near the compressed air module reduces line losses. Electricity can be generated using modular gensets so the cost of electricity substations and high voltage trunk lines to underground are replaced or supplemented by using modular underground LA electricity generation. Stirling engines are capable of operating efficiently between the LA and ambient temperatures at high efficiencies and can be used for heavy duty pumping, milling or electricity generation. The efficiency of Stirling engines can be further increased by using a solar collector with a high temperature heat storage system, such as oil or nitrate salts, to increase the efficiency. All uses of $L A$ benefit from a higher rock temperature as the depth increases because the Carnot efficiency of a heat engine increases as the temperature difference increases.

Numerical modelling of the interaction between the LA introduced to a ventilation flow and the rate of heat absorption from the underground rock surfaces is presented. The effect on ventilation pressure due to the expansion of the $L A$ is described.

\section{Introduction}

The mining industry is a major energy user; thus, mining companies are encouraged to both implement energy efficiency measures and consider cost effective means of generating power. The scale of mining operations places them in a position to produce power and become part of a distributed energy system. 
A key element to a distributed energy system is a means of energy storage. Energy storage provides the opportunity for arbitrage between the peak and off-peak energy prices or peak smoothing. Energy storage systems also serve to enhance the stability of intermittent sources such as wind or solar power generation. Examples of energy use in mining demonstrate the potential for energy production as a scheme that can provide security of supply to the operations and may improve the corporate bottom line through sales of energy to various markets. The energy costs for mining projects in the US are estimated to be $15 \%$ of the total cost of all US based production, while in Brazil and South Africa the consumption of energy for mining represents 6 and $4 \%$ of the total country energy production respectively (Mclvor 2010).

Governments are either encouraging or obliging mining companies to reduce energy demand. The South African Department of Minerals and Energy set a 2015 target for the mining industry to reduce demand by 15\%. In Australia; mining corporations are obligated to comply with the equipment energy efficiency (E3) programme, which requires equipment purchases to meet regulated minimum energy use standards (Department of Climate Change and Energy Efficiency 2010). To address their energy security in South Africa, Lonmin PLC set an energy efficiency improvement target of 10\% from 2007 levels over a five year period. Vale has invested in natural gas power, biodiesel, owns a stake in eight hydroelectric plants and has pursued a partnership with the national development Bank of Brazil, Vale Soluções em Energia (VSE), which has an investment profile of USD $720 \mathrm{~m}$ with a particular focus on distributed energy. Distributed energy production is the next phase of energy supply security and storage is a significant part of the system.

Mining companies with a longer view to energy economics are considering energy production as a part of their core business. The life-of-mine (LOM) for many mining projects may compare favourably to the expected life of an energy production project. If considered as separate projects, the company could enjoy the benefits of government subsidies for small-scale power production. An energy supply project, such as a wind turbine generation plant with an expected life of 25 years, coupled with a mining project with a LOM of 15 years, may continue to provide revenue for years after closure. The size of the energy project dictates the revenue available upon closure and a sufficiently large project designed to ensure energy security may even generate revenue during operations, provided the geography is conducive to grid connection. Revenue generation upon closure is a convenient means of financing the closure plan and the energy project may actually be sufficient collateral to secure the mining project closure bond with the government (Cluff et al. 2013). Although the focus of most companies is currently on improvement of efficiencies, the visionary CEOs are considering distributed energy as an appropriate response to increasing energy costs and to secure supply.

Distributed energy generation coupled with a robust energy storage scheme is the way forward if the desired outcome is a sturdy power grid. The notion that a distributed energy generation system may be capable of a more dynamic response to sudden changes or surges, compared to centrally produced power, was made abundantly clear during the North American power failure of 2003. An excerpt from the Final Report on the August 14, 2003 Blackout to the North American Electric Reliability Council Board of Trustees illustrates the problem with our current grid structure.
"A series of line outages in northeastern Ohio starting at 15:05 caused heavy loadings on parallel circuits, leading to the trip and lock-out of the Sammis-Star line at 16:05:57. This was the event that triggered a cascade of line outages on the high voltage system, causing electrical fluctuations and generator trips such that within seven minutes the blackout rippled from the Cleveland-Akron area across much of the northeastern United States and Canada. By 16:13, more than 508 generating units at 265 power plants had been lost, and tens of millions of people in the United States and Canada were without electric power." (Hilt et al. 2003)

Implementation of combined heat and power (CHP) systems, which rely on natural gas (NG) to produce electricity, is a stride toward energy reliability because in the event of an electrical power disruption the natural gas is usually available (Cluff 2014). This would allow the company a secure energy supply for critical systems, the opportunity to employ high efficiency systems on site due to the lower price per $\mathrm{kWh}$ for electricity produced by NG and the use of the waste heat from the CHP for other purposes. Renewable 
energy systems such as wind and solar generation are also potential distributed energy systems supply candidates due to the scalability of these systems and the complimentary nature of using both simultaneously.

\section{Liquid air energy systems and energy storage}

Mining is an energy intensive undertaking, but deeper mining consumes even more energy due to increased thermal influence and transport distances of material, personnel, services and infrastructure. The expected distribution of energy in a deep mine, shown in Figure 1 for a model of a 5,000 m deep mine, is based on the MinEcon economic modelling package used by AngloGold Ashanti in an analysis of future energy use in their deep mines (AngloGold 1999). The energy expenditures that can be targeted by LA are the ventilation and cooling, compressed air, pumping and portions in the neighbourhood of $50 \%$, of hoisting, crushing, grinding and mining transportation. The impact is that about $75 \%$ of the energy use in the operating mine can be influenced by the use of LA.

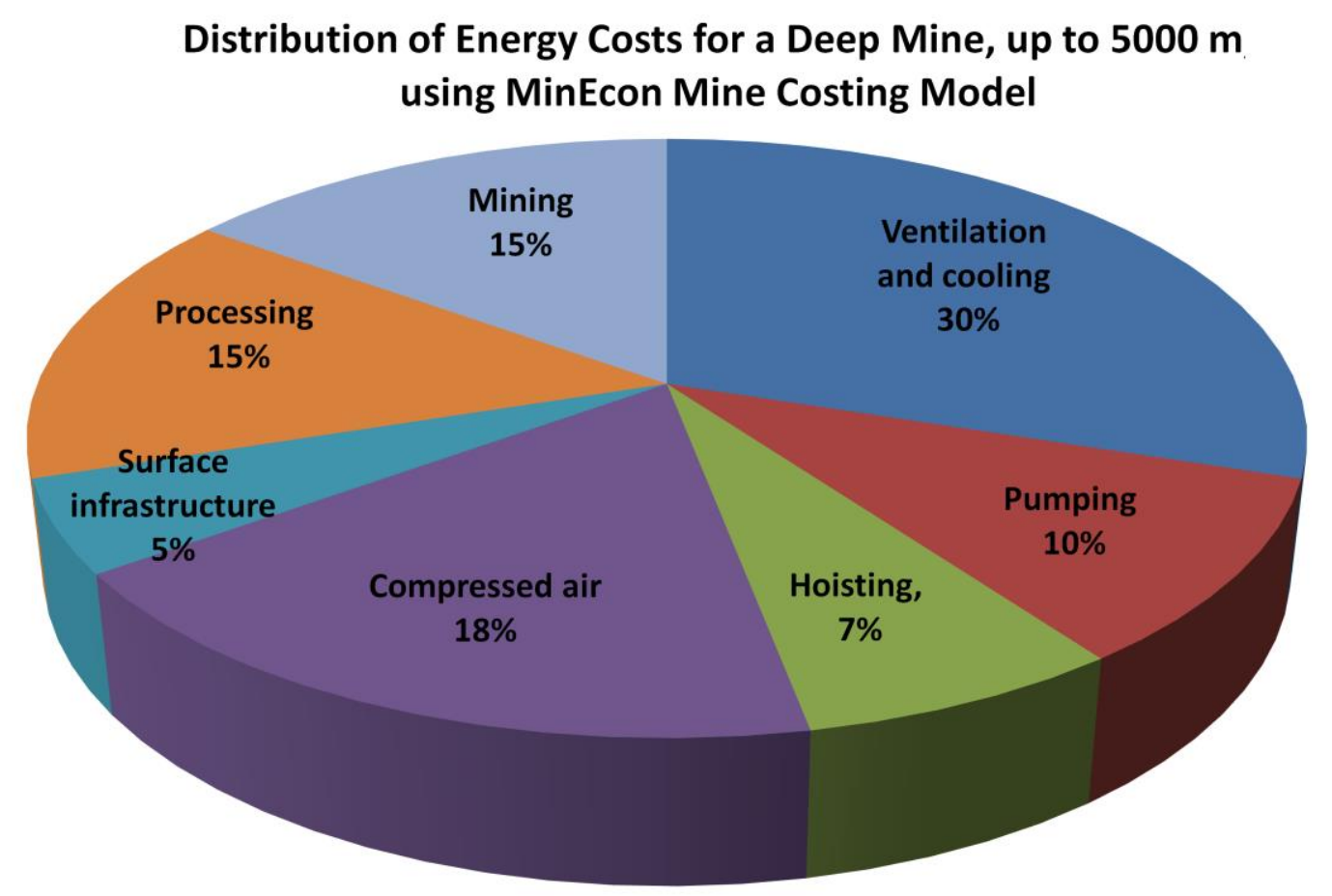

\section{Figure 1 Energy distribution for a deep mine, up to 5,000 m, according to MinEcon model (AngloGold 1999)}

The concept of using liquid air as an energy storage vector is currently the subject of a $300 \mathrm{~kW}$ pilot plant at the Highview Power Storage in conjunction with Scottish \& Southern Energy at the Slough, UK Heat \& Power site (Strahan et al. 2013). The infrastructure associated with liquid air is mature; the concept was initially developed in 1895 and Linde received a patent in 1903 for his process of liquefying air by compressing it and then allowing it to rapidly expand causing a throttling process and rapid cooling. The Highview system in the current configuration is a complete integrated cycle, which uses ambient air and electrical power to produce the liquid air. In this configuration, electricity powers an air liquefaction plant to refrigerate air to its liquid state, but wind powered compressors or electrical power from either wind turbines or solar voltaic systems could be the main power source. The liquid air, stored in an insulated tank at low pressure, is the energy storage reservoir. Liquid air is drawn from the tank into a heat exchanger, as power is required. The low temperature of the cryogenic fluid allows for ambient temperatures to be a sufficient heat source, but the addition of even low-grade waste heat readily causes a rapid expansion of the fluid to a gas, with an increase in efficiency. If contained in a cylinder the high-pressure gas can do work 
or the expanding gas can drive a turbine and generator to produce electricity. Consequently, the waste heat from a CHP system is an ideal heat source for the conversion of the liquid air to energy.

Regardless of the LA production modality, this concept capitalises on the availability of a source of liquid air beyond use as an energy storage vector. A LA facility allows for underground ventilation associated with cooling to offset auto-compression, the use of modular compressed air and electrical production facilities at depth and the opportunity to deploy a Stirling engine or the Dearman engine power train in standard mine equipment. The Stirling engine is amenable to stationary applications in lieu of electrical motors such as water pumps, conveyor systems, hoisting systems or driving an electrical generator. The Dearman Engine is a motive power system able to drive large equipment, but could also be employed to provide pumping, hoisting or conveyance. These energy benefits are enhanced by the notion of the ultra-low greenhouse gas (GHG) emissions from any liquid air systems in use and the reduction in cost compared to fossil fuel engines results in a much greener mine.

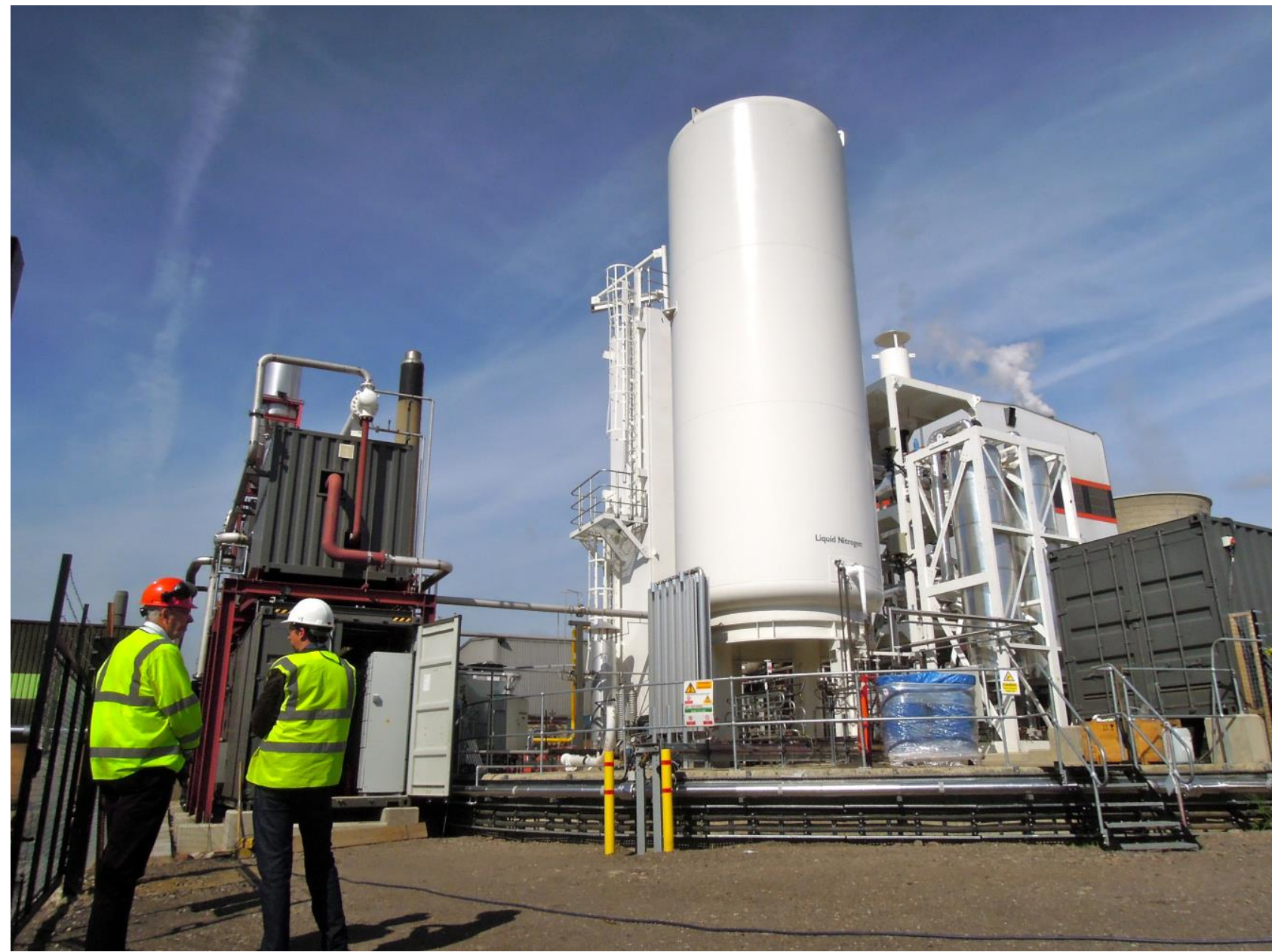

\section{Figure 2 The 300 kW Highview Power Storage pilot plant in Slough, UK (reprinted courtesy of Highview Power Storage)}

The production and storage of liquid air for use as an energy storage vector is set out in the Highview Power Storage $300 \mathrm{~kW}$ pilot plant at Slough shown in Figure 2. The system consists of three main elements: charging, storage and power recovery. The air liquefaction plant refrigerates the air to its liquid state. The liquid is then stored in an insulated low-pressure tank. The low-pressure storage is the energy store and the main repository for all secondary LA uses. When power is required, liquid air is drawn from the tank and pumped at high pressure to a heat exchanger, where the addition of heat, turns the cryogen into a high-pressure gas. The high-pressure gas is then used to drive a turbine and generator to deliver electricity to the company or the grid. The $300 \mathrm{~kW}$ installation in Slough, UK uses waste heat from the pre-existing biomass power station proximal to the LA storage pilot plant. The performance data from Highview 
suggests that the heat from the biomass plant is converted into power at an efficiency of $50-60 \%$ (Strahan et al. 2013). The addition of waste heat from the biomass plant serves to increase the highest temperature with a corresponding increase in overall system efficiency because it depends on the highest and lowest temperatures.

A liquid air production facility and storage tanks are systems that mining companies can implement with little risk due to the maturity of the technology used to create a new system. The Highview system is assembled from components commonly used in the industrial gases and electricity generating industries, but combined in a novel form to create a liquid air energy storage system. The reliability was determined to be $95 \%$ with a start-up time to reach expected output of only 2.5 minutes. The Highview Cryogenset shares many characteristics of diesel gensets and open cycle gas turbines, such as low capital cost and relatively fast start up times, but with the additional advantage of lower carbon emissions. Even when the liquid air is generated from off-peak electricity, it is likely to be less carbon intensive than diesel or gas and inexpensive due to the combination of CHP and liquid air technologies.

In the following sections, the integration of liquid air energy storage systems into a mining operation are outlined for use in conjunction with or to supply: ventilation air, chilling capacity, compressed air delivery, underground electricity production, pumping, conveyance or power generation via a Stirling engine and the use of the Dearman engine for motive force.

\section{$3 \quad$ Liquid air ventilation concepts}

Ventilation is a significant cost for any mining operation, but as the depth of the mine increases, the ventilation costs increase because frictional losses over longer distances travelled for downcast and upcast air, auto-compression heating as the depth increases and the higher rock surface temperatures that contribute to the heat that must be removed from the underground workings.

\subsection{Auto-compression}

Auto-compression causes a temperature increase of the ventilation air due to increasing pressure as it descends to deep operating levels. Increased pressure at depth causes the volume to contract with a resulting increase in density of the air parcel. The energy per unit mass remains constant; thus, the energy per unit volume increases. This effect causes an increase in the air temperature that becomes a more significant design variable as the depth increases. Since the heat is not rapidly transmitted to the ambient rock, the thermodynamic process of adiabatic compression describes the effect mathematically and the adiabatic temperature lapse rate is the temperature change per distance. The change in internal energy $\Delta U$ plus the work done $\Delta \mathrm{W}$ equals the heat transfer $\Delta \mathrm{Q}$. For an adiabatic compression, the heat transfer $\Delta \mathrm{Q}$ is zero so, $\Delta U=-\Delta \mathrm{W}$, that is the work is done on the air resulting in an increase in internal energy, which is accounted for by an increase in temperature. Since the auto-compression effect is sensitive to the surface conditions it is recommended that the temperature and pressure at surface along with pressure measurements at all exit levels and at selected points along the downcast shaft are measured continuously with remote sensors installed at the locations, tabulated and stored for future study. Due to this sensitivity of temperature and density to the surface conditions and those experienced during descent in the shaft, they should be measured or calculated based on the measured pressures. Using the concepts of adiabatic compression the temperature and density should be modelled as follows:

$$
\begin{gathered}
T_{2}=T_{0}\left(1-(\nu-1 / \gamma)\left(Z / Z_{0}\right)\right. \\
T_{2}=T_{1}\left(P_{2} / P_{1}\right)^{(\gamma-1 / v)} \\
\rho_{2}=\rho_{0}\left(1-(\nu-1 / \gamma)\left(Z / Z_{0}\right)^{1 /(1-v)}\right. \\
Z_{0}=R T_{0} / \mu g
\end{gathered}
$$


Where:

$$
\begin{array}{ll}
T_{0}, \rho_{0} \text { and } P_{0}= & \text { surface temperature, density and pressure respectively. } \\
T_{2}, \rho_{2} \text { and } P_{2}= & \text { temperature, density and pressure at depth } Z \text { respectively. } \\
V & =\text { gas constant }=1.4 \text { for dry air, polytrophic index can be } 1.37 \text { for upcast or } 1.43 \text { for } \\
& \text { downcast. } \\
& =\text { universal gas constant }=8.3144621 \mathrm{~J} / \mathrm{mole}-\mathrm{K} . \\
\mathrm{R} & =\text { molecular mass }(0.8)(28)+(0.2)(32)=28.8 \mathrm{~g} / \mathrm{mole} . \\
\mathrm{g} & =\text { gravitational acceleration }=9.81 \mathrm{~m} / \mathrm{s}^{2} .
\end{array}
$$

A few methods, the exponential relation, the adiabatic gas law, the scale height method and the sum of the measured pressures between levels can be used to calculate the pressure profile with depth. Since pressure measurements are preferred, a calculation based on the density and the volume of segments from the surface is included for comparison. The ventilation survey method used the densities calculated by Equation (3) and averaged the mass in a volume of a $5 \mathrm{~m}$ radius shaft at $500 \mathrm{~m}$ intervals.

$$
\begin{gathered}
P_{2}=P_{0}\left(1-(\nu-1 / \gamma)\left(Z / Z_{0}\right)^{v /(1-v)}\right. \text { adiabatic law method } \\
P_{2}=P_{0}\left(1-\left(Z / 3.5 Z_{0}\right)^{3.5} \quad\right. \text { scale height method } \\
P_{2}=P_{0} e^{-z / Z o} \text { simple exponential method }
\end{gathered}
$$

For a surface temperature of $293 \mathrm{~K}\left(9.85^{\circ} \mathrm{C}\right)$ the adiabatic gas law method and the scale height method provide identical results over the range of depth while the sum of the simulated ventilation survey is slightly higher and the simple exponential method overestimates. The calculated lapse rates are $0.9714 \mathrm{~K} / 100 \mathrm{~m}$ using the adiabatic gas law and the scale height method using Equation (1) and using Equation (2) with the pressures calculated from Equation (5). The simulated ventilation survey method gave $0.9847 \mathrm{~K} / 100 \mathrm{~m}$ at $100 \mathrm{~m}$ rising to $0.9905 \mathrm{~K} / 100 \mathrm{~m}$ at 5,000 m, which represents a very small deviation for averaging over $500 \mathrm{~m}$ drops in the shaft. These values compare favourably to $0.0098^{\circ} \mathrm{C} / \mathrm{m}$ (Navarro-Torres \& Singh 2011), and similarly $5.4^{\circ} \mathrm{F}\left(-14^{\circ} \mathrm{C}\right)$ per $1,000 \mathrm{ft}(300 \mathrm{~m})$. (Bossard 1993) for dry air. The calculation of the dry lapse rate over each interval of the ventilation survey in the downcast shaft is a good method of revealing the presence of water in the shaft because the dry air lapse rate will decrease as more evaporative cooling occurs. A typical WB lapse rate is $0.456 \mathrm{~K} / 100 \mathrm{~m}$ and calculation of the WB lapse rate is an indicator of heat transfer to strata over an interval. The unique characteristics of a given shaft can then be represented by regression equations specific to the shaft, which can be used for control feedback of the ventilation systems response to changing conditions at surface or underground.

The temperature, density and pressure at depth are all sensitive to the initial surface temperature through the variable $Z_{o}$ so this must be considered in each scenario. For an inlet temperature of $293 \mathrm{~K}$ and given the value of the air density at $3,000 \mathrm{~m}$, a flow of about $947 \mathrm{~m}^{3} / \mathrm{s}$ at depth would require $1,200 \mathrm{~m}^{3} / \mathrm{s}$ from the surface inlet. The temperature increase would be $29.14^{\circ} \mathrm{C}$ and using specific heat capacity of $1.005 \mathrm{~J} / \mathrm{gK}$ results in a heat dissipation requirement of $53.90 \mathrm{MW}$ for an inlet air temperature of $293 \mathrm{~K}$.

The amount of heat to be ejected based on the initial temperature and the target temperatures are shown for a $1,200 \mathrm{~m}^{3} / \mathrm{s}$ flow in the last three columns of Table 1 . At deeper exit levels, the effect is increasingly pronounced. For mines deeper than about $2,000 \mathrm{~m}$, subject to higher surface temperatures and requiring higher ventilation flow, the heat introduced due to the auto-compression effect becomes a more significant design variable.

Considering the use of liquid air to offset the heat will allow a reduction in amount of air taken at the inlet so the main fans can run at a lower operating power. Consequently, there is less power consumption at the main fans and a saving due to reduced friction losses at lower airflow rates or a designed reduction of the size of the ventilation raise may be the choice to reduce infrastructure costs. 
Liquid air expands by a factor of $0.71 \mathrm{~m}^{3}$ (gas) $/ \mathrm{L}_{\text {(liq) }}\left(\mathrm{m}^{3} / \mathrm{L}\right)$ by absorbing the latent heat of vaporisation of $198.7 \mathrm{KJ} / \mathrm{kg}$ from the ambient surroundings. After the initial conversion from liquid to gas, the temperature is near $78.65 \mathrm{~K}$, just above the boiling point of the liquid and the ideal gas density is $4.489 \mathrm{~kg} / \mathrm{m}^{3}$. The expansion factor depends on the final temperature and pressure; from $78.65 \mathrm{~K}$ to $293 \mathrm{~K}$ it is 3.73 resulting in $700 \mathrm{I}$ of gas per 1 litre of liquid at standard atmospheric pressure.

Table 1 Auto-compression calculations for depth to 5,000 m

\begin{tabular}{|c|c|c|c|c|c|c|c|c|}
\hline \multirow{2}{*}{$\begin{array}{c}\text { Depth } \\
\text { (m) }\end{array}$} & \multirow{2}{*}{$\begin{array}{c}\text { Air } \\
\text { density } \\
293 \mathrm{~K}\end{array}$} & \multirow{2}{*}{$\begin{array}{c}\begin{array}{c}\text { Pressure } \\
\text { calculated } \\
293 \mathrm{~K}\end{array} \\
(\mathrm{kPa})\end{array}$} & \multicolumn{3}{|c|}{$\begin{array}{c}\text { Temperature at exit for } \\
\text { selected initial temperatures } \\
\text { shown at top of row }\end{array}$} & \multicolumn{3}{|c|}{$\begin{array}{l}\text { Heat dissipation for a } 1,200 \mathrm{~m}^{3} / \mathrm{s} \text { inlet } \\
\text { flow and target temperature of } 293 \mathrm{~K} \\
\text { (MW) }\end{array}$} \\
\hline & & & (K) & (K) & (K) & $T_{i}=283 \mathrm{~K}$ & $T_{i}=293 \mathrm{~K}$ & $\mathrm{~T}_{\mathrm{i}}=300 \mathrm{~K}$ \\
\hline 0 & 1.210 & 101.325 & 283 & 293.00 & 300.00 & & 0.00 & 10.21 \\
\hline 100 & 1.220 & 102.506 & 283.97 & 293.97 & 300.97 & & 1.43 & 11.73 \\
\hline 500 & 1.261 & 107.326 & 287.86 & 297.86 & 304.86 & & 7.38 & 18.03 \\
\hline 800 & 1.292 & 111.047 & 290.77 & 300.77 & 307.77 & & 12.11 & 23.01 \\
\hline 1,000 & 1.313 & 113.578 & 292.71 & 302.71 & 309.71 & & 15.38 & 26.46 \\
\hline 1,500 & 1.366 & 120.084 & 297.57 & 307.57 & 314.57 & 7.53 & 24.01 & 35.54 \\
\hline 2,000 & 1.421 & 126.854 & 302.43 & 312.43 & 319.43 & 16.15 & 33.29 & 45.28 \\
\hline 2,500 & 1.477 & 133.891 & 307.28 & 317.28 & 324.28 & 25.44 & 43.24 & 55.71 \\
\hline 3,000 & 1.534 & 141.203 & 312.14 & 322.14 & 329.14 & 35.40 & 53.90 & 66.85 \\
\hline 3,500 & 1.592 & 148.796 & 316.99 & 327.00 & 334.00 & 46.08 & 65.28 & 78.72 \\
\hline 4,000 & 1.652 & 156.676 & 321.86 & 331.86 & 338.86 & 57.49 & 77.41 & 91.35 \\
\hline 4,500 & 1.713 & 164.849 & 326.71 & 336.71 & 343.71 & 69.65 & 90.31 & 104.77 \\
\hline 5,000 & 1.775 & 173.323 & 331.57 & 341.57 & 348.57 & 82.59 & 104.00 & 118.99 \\
\hline
\end{tabular}

As an example, consider a need for $793 \mathrm{~m}^{3} / \mathrm{s}$ at a depth of $3,000 \mathrm{~m}$, based on the results in Table 1, a flow of $1,000 \mathrm{~m}^{3} / \mathrm{s}$ at the surface is required and for a target temperature of $293 \mathrm{~K}$ and a surface temperature of $300 \mathrm{~K}$ the heat discharge required is $55.41 \mathrm{MW}$. A combination of $707.4 \mathrm{~m}^{3} / \mathrm{s}$ from the surface and $85.6 \mathrm{~m}^{3} / \mathrm{s}$ from liquid air provides a final temperature of $293 \mathrm{~K}$. The reduction in demand from the surface is from 1,000 to $891 \mathrm{~m}^{3} / \mathrm{s}$ and the amount of heat to be discharged is reduced from $55.41 \mathrm{MW}$ to $38.4 \mathrm{MW}$. The increase in energy acquired by the LA, the potential energy from the surface to depth, is accounted for by the evaporation of $10.53 \mathrm{~g}$, which is less than the expected off gassing let out into the airflow through pressure valves along the cryo-tubing over a 3,000 $\mathrm{m}$ drop, and so is ignored.

Similarly, the same calculations for a surface temperature of $300 \mathrm{~K}$ and a target temperature of $293 \mathrm{~K}$ at $5,000 \mathrm{~m}$ would require $1,154 \mathrm{~m}^{3} / \mathrm{s}$ from surface and would need to discharge $113.47 \mathrm{MW}$. This demand is met by a combination of $641 \mathrm{~m}^{3} / \mathrm{s}$ from surface and $152 \mathrm{~m}^{3} / \mathrm{s}$ from LA, which reduces the surface demand to $932 \mathrm{~m}^{3} / \mathrm{s}$ and the heat burden to $61.75 \mathrm{MW}$, by introducing a flow of $182.4 \mathrm{~kg} / \mathrm{s}$ of liquid air at depth with $24 \mathrm{~g} / \mathrm{s}$ liberated from the flow.

For multiple levels, the flows are calculated independently for each level taking into account the auto-compression effect at the depth in question. Due to the vigorous mixing of the co-flows, the energy is drawn predominantly from the incoming ventilation air so the target temperature is easily calculated, but deviations are indicators of heat transfer of evaporation effects. A MATLAB computer program is currently in progress to incorporate liquid air into ventilation calculations and ventilation survey measurements. 
The addition of liquid air to a ventilation flow is similar to the addition of a booster fan. In this case, let the diameter of the ventilation raise be $12 \mathrm{~m}$, giving an area of $113 \mathrm{~m}^{2}$ and a flow velocity of $8.84 \mathrm{~m} / \mathrm{s}$ at the surface to supply the $793 \mathrm{~m}^{3} / \mathrm{s}$ to the $3,000 \mathrm{~m}$ level. By splitting the flow between the LA and surface drawn air, the raise only needs to provide $891 \mathrm{~m}^{3} / \mathrm{s}$ so the flow velocity can be reduced to $7.87 \mathrm{~m} / \mathrm{s}$ or the diameter of the raise set to $9.9 \mathrm{~m}$ with a velocity of $12.2 \mathrm{~m}^{3} / \mathrm{s}$. At the level, $707.4 \mathrm{~m}^{3} / \mathrm{s}$ is mixed with $85.6 \mathrm{~m}^{3} / \mathrm{s}$ so the flow increase provides increased ventilation pressure without actually adding a fan to the system and since the LA is completely dry a reduction in the relative humidity.

If all parameters remain constant, the main fans will only need to supply $89.1 \%$ and $80.7 \%$ of the flow for the $3,000 \mathrm{~m}$ and for the $5,000 \mathrm{~m}$ scenario respectively. The reduced flow from the surface and reduced demand for booster fans at the level both provide savings of power consumption and infrastructure for the entire life of mine.

Liquid air can also be introduced into the airflow at strategic locations throughout the operating level further reducing the need for booster fans and providing chilling to offset the effect of heat conduction from the rock surface. Since the liquid air is being used for several other aspects of the operations, the cost of production is distributed over these departments; significant long-term savings in power consumption should be realised.

\section{$4 \quad$ Ventilation and rapid chilling of rock surfaces at depth}

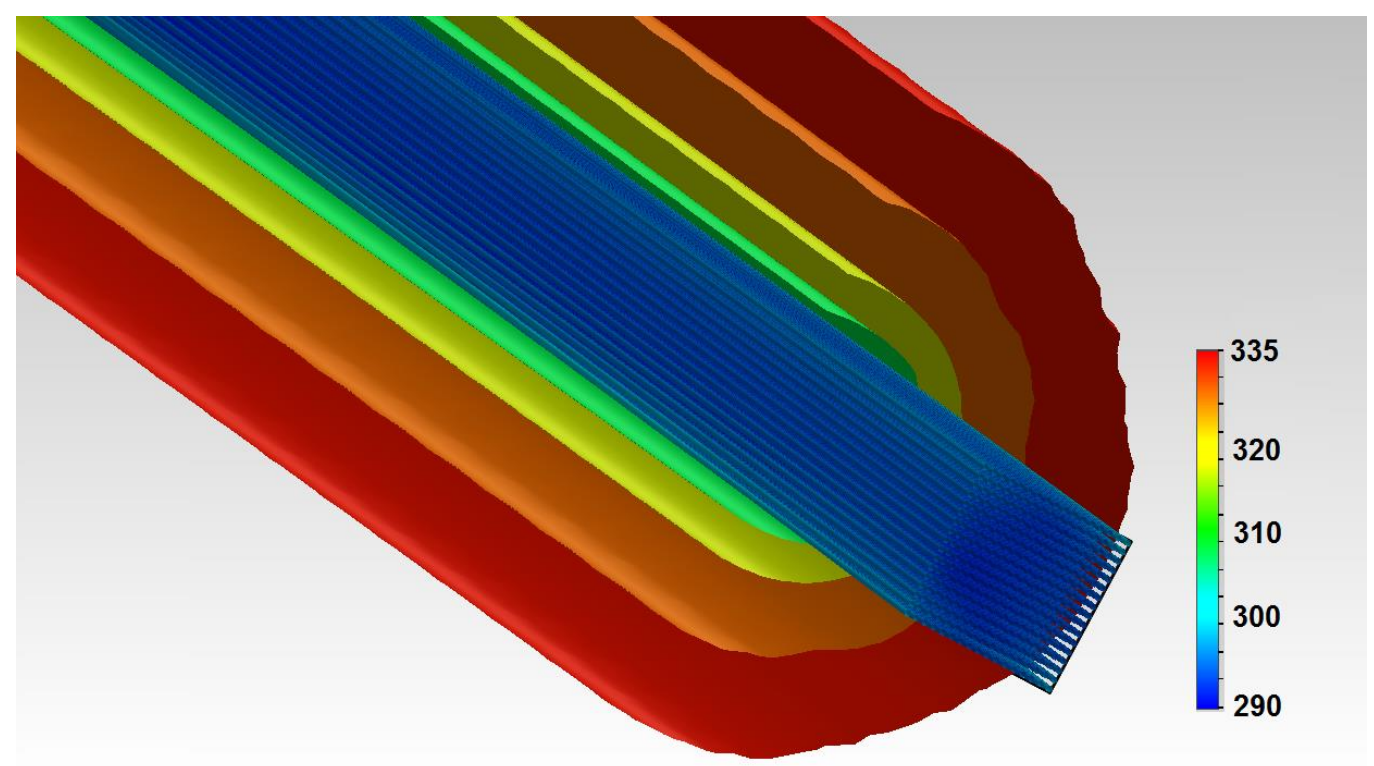

Figure 3 Airflow shown as blue flow trajectories with isotherms in the rock at $334 \mathrm{~K}$ (red), $330 \mathrm{~K}$ (orange), $320 \mathrm{~K}$ (yellow) and $310 \mathrm{~K}$ (green) located in the exit of a $255 \mathrm{~m}$ long drift and 7.4, 4.6, 2.1 and $0.95 \mathrm{~m}$ from the rock air interface (RAl) respectively

Once the air has reached the level, the movement through the network is subject to increasing rock skin temperatures as the deeper deposits are mined. The impact of liquid air at depth is realised by the opportunity to introduce chilling at various points in the network while also providing ventilation pressure. A numerical model, seen in Figure 3, comprised of a rock with a density of $2,700 \mathrm{~kg} / \mathrm{m}^{3}$, specific heat capacity of $900 \mathrm{~J} / \mathrm{kg} \mathrm{K}$ and thermal conductivity of $3 \mathrm{~W} / \mathrm{m}-\mathrm{K}$ was created to study the effect of heat conduction to the air from the rock.

The bulk distributed temperature is initially at $335 \mathrm{~K}\left(61.85^{\circ} \mathrm{C}\right)$, and the outer boundary of the rock was maintained at $335 \mathrm{~K}$ to simulate the distant heat sink of the rock. The air has an initial temperature of $290 \mathrm{~K}\left(16.85^{\circ} \mathrm{C}\right)$, a relative humidity of $55 \%$, inlet velocity of $1.5 \mathrm{~m} / \mathrm{s}$ and standard thermal properties. The 
dimensions of the model are a $5 \times 5 \mathrm{~m}$ square drift embedded in a $30 \times 30 \mathrm{~m}$ square rock with a length of $255 \mathrm{~m}$.

The fluid temperature reached a maximum of $309.87 \mathrm{~K}\left(36.72^{\circ} \mathrm{C}\right)$ while the rock reached a minimum temperature of $295.94 \mathrm{~K}\left(22.79^{\circ} \mathrm{C}\right)$. The computational fluid dynamics numerical modelling (CFD) is a means of determining design variables such as the temperature of the air at exit from the drift after the rock has reached a steady state skin temperature such as the result seen in Figure 3 . In a deep mine, the time required to reach a steady state temperature and the length of drift that provides a sufficient air temperature rise to require chilling are both key ventilation design parameters where liquid air release to the airflow would be advantageous.

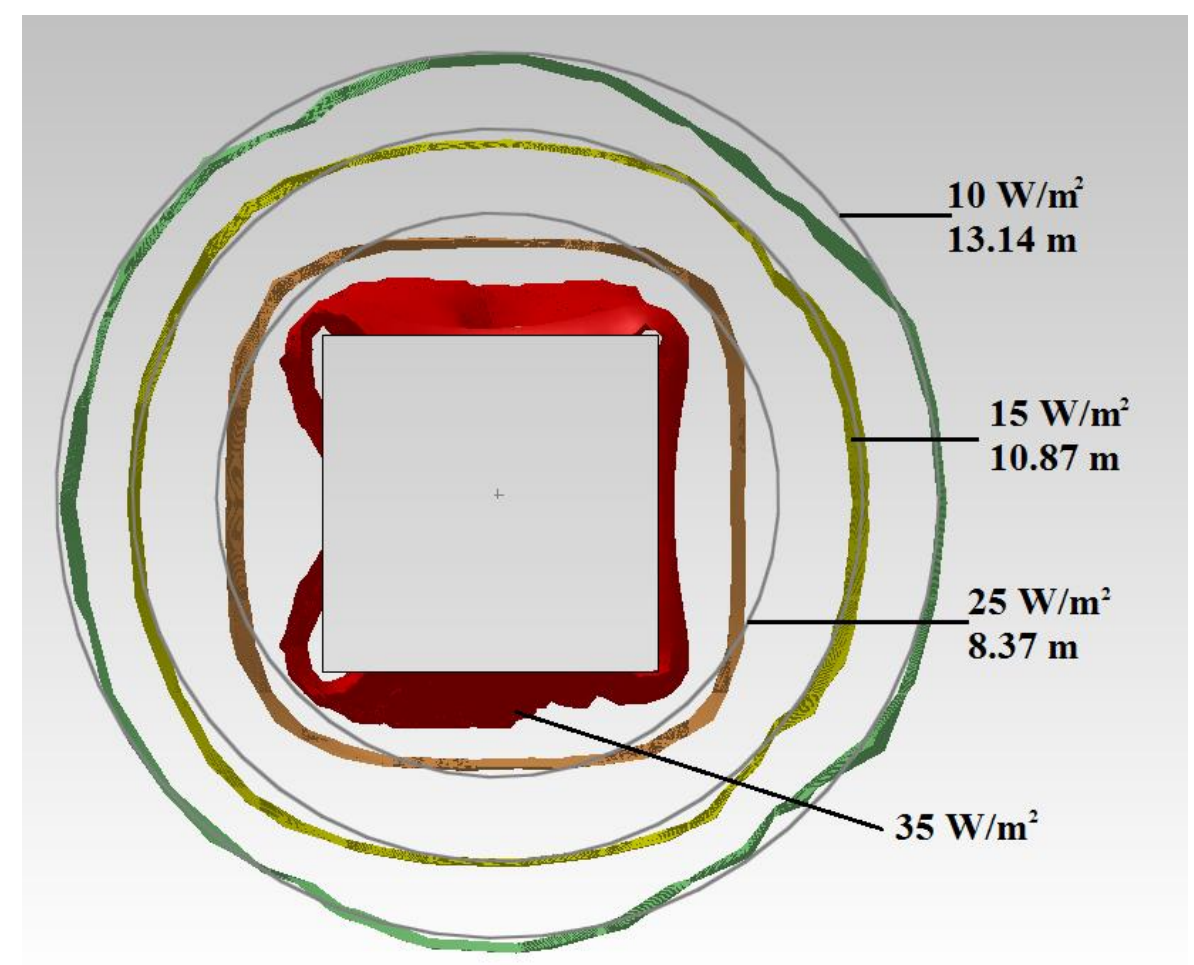

Figure 4 Inlet of airflow with heat flux located in the rock at $35,25,15$ and $10 \mathrm{~W} / \mathrm{m}^{2}$

Figures 3 and 4 are both steady state solutions after 57.87 days from the initiation of the airflow, the final iteration of the simulation, and show the thermal state of the rock at that time. The isotherms in the rock, shown in Figure 3, are 7.4, 4.6, 2.1 and $0.95 \mathrm{~m}$ from the rock air interface (RAI) for $334 \mathrm{~K}\left(60.85^{\circ} \mathrm{C}\right)$, $330 \mathrm{~K}\left(56.85^{\circ} \mathrm{C}\right), 320 \mathrm{~K}\left(46.85^{\circ} \mathrm{C}\right)$, and $310 \mathrm{~K}\left(36.85^{\circ} \mathrm{C}\right)$ respectively. The distance from the RAl of the surfaces with constant heat flux, shown in Figure 4 with approximate circles of constant heat flux, reveal that as the distance from the face and the resultant area that the heat flux crosses increase, the heat flux decreases correspondingly. The maximum heat flux determined at the surface during the simulation was $107.45 \mathrm{~W} / \mathrm{m}^{2}$ and the surface transfer coefficient was $9.02 \mathrm{~W} / \mathrm{m}^{2}-\mathrm{K}$. These data are from a singular simulation; however, the model can now be modified to provide insight into several other scenarios or be used to perform a sensitivity analysis simply by changing the boundary or initial conditions. It is important to note that CFD will play a larger role in calculating the thermal aspects for the ventilation design of deeper mines, due to increased heat loads, larger variations in air densities and conduction of heat from the RAI. If plans to implement ventilation on demand (VOD) are being considered, CFD modelling will be instrumental in the determination of conditioning times required for hot drifts to chill to a reasonable state for good working conditions to exist in the fresh airflows.

To emphasise this point, plots of the air temperature at the centre and bottom-centre of the horizontal drift, but at the same distance from the entrance, are shown in Figure 5, which could be what is returned from an improperly performed ventilation survey, while Figure 6 is a detailed ventilation survey comprised 
of 25 points taken at a cross-section. In Figure 5, it is clear that the centre airflow is well mixed, which is evident from the smooth temperature rise and lesser temperature increase along the drift, compared to the bottom-centre where a higher temperature is observed at exit and fluctuations due to turbulence and proximity to the RAl are apparent. At 0.35 days from the initiation of airflow, the temperature, over the length of the drift at the centre, has increased from $290 \mathrm{~K}\left(16.85^{\circ} \mathrm{C}\right)$, at the entrance to $303.10 \mathrm{~K}\left(29.95^{\circ} \mathrm{C}\right)$, at the exit while the same measurement at the bottom-centre has increased to $308.56 \mathrm{~K}$. It is often considered sufficient to take a few measurements and average the values for a ventilation survey; however, CFD modelling shows a wide temperature variation, due to the interaction at the RAI.

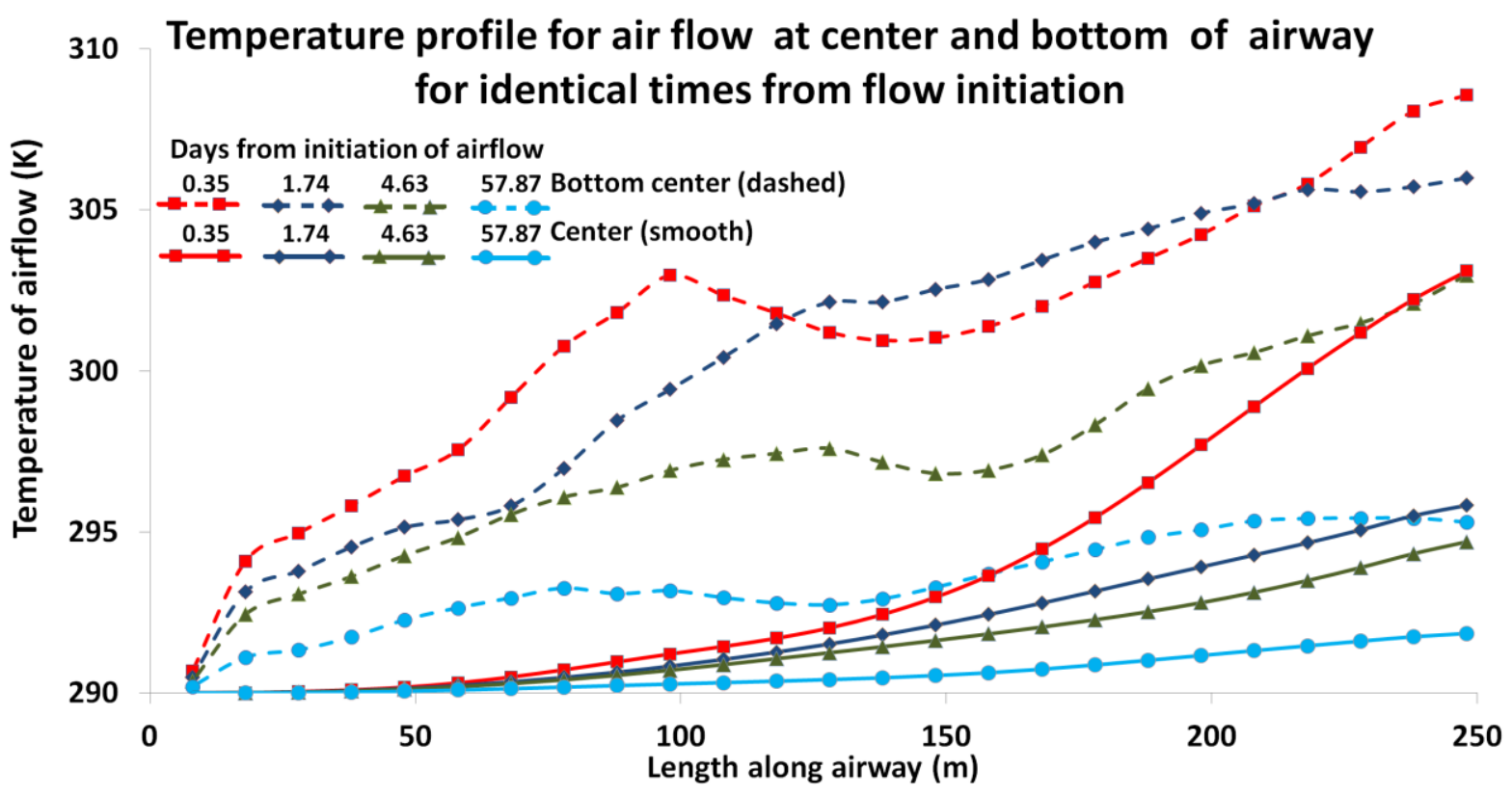

Figure 5 Temperature measured at identical selected times from initiation of air flow for the centre of the flow (smooth) and the bottom-centre (dashed)

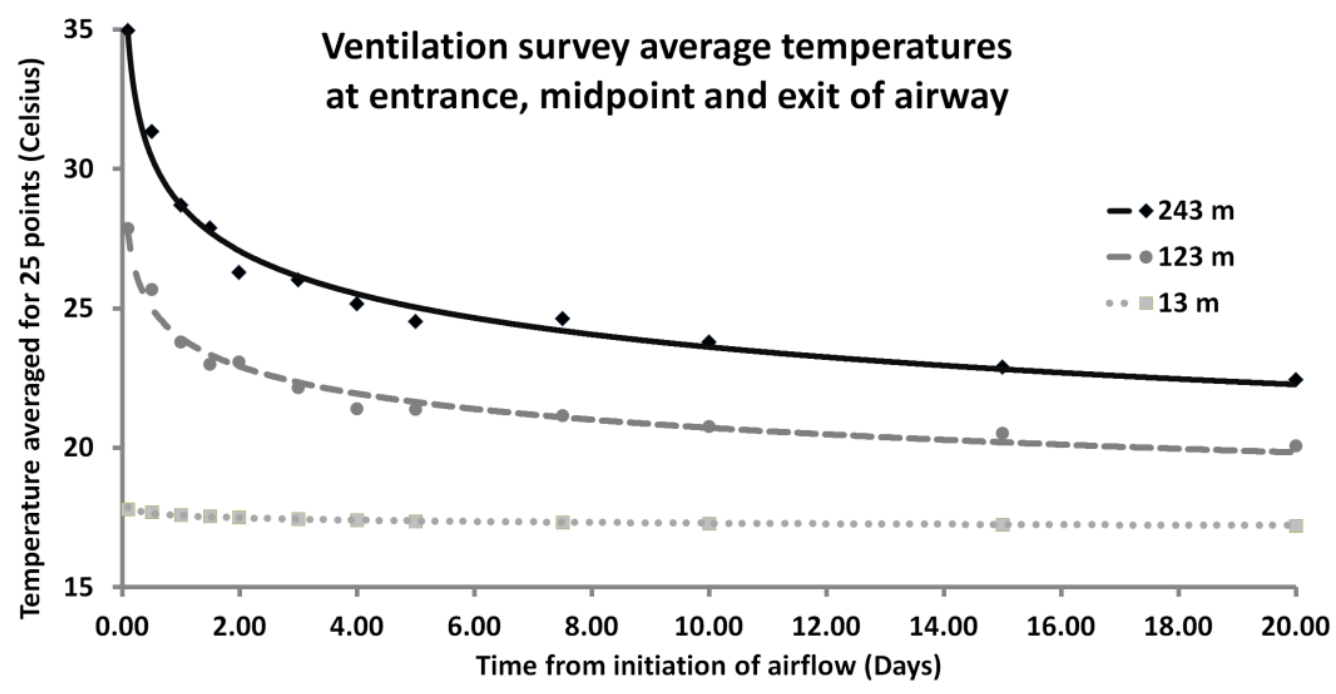

Figure 6 Ventilation survey taken from flow simulation at 13, 123 and $243 \mathrm{~m}$ from the entrance of the drift. For each measurement, a cross-sectional grid of 25-point measurements are averaged for each time from the initiation of the flow

A LA ventilation system inserted at the entrance or a strategic point along the drift to provide cool air is similar in effect to that used in the case of auto-compression, but requires more control of the mixing due to the proximity of personnel. Observation of the plot in Figure 6 , a detailed ventilation survey comprised of 25 points taken at 13, 125 and $243 \mathrm{~m}$ cross-sections along the flow, shows the temperature profile due 
to the introduction of cold air at the entrance. The $290 \mathrm{~K}\left(16.85^{\circ} \mathrm{C}\right)$ airflow from a LA release was introduced at the entrance of the drift. The time for the drift to become conditioned to a reasonable working environment depends on the type of work being undertaken; clearly, work that is more vigorous requires lower temperatures. If the specification in this drift is for a vigorous work place with a WBT of $24^{\circ} \mathrm{C}$ and the relative humidity is $70 \%$ then the target DBT is $28.5^{\circ} \mathrm{C}$. These conditions occur virtually instantaneously at the entrance and after about 1.5 days at the exit of the $255 \mathrm{~m}$ drift. The air produced at the entrance was $16.85^{\circ} \mathrm{C}$ and settles to a value of $22.4^{\circ} \mathrm{C}$ at the end of the drift. The use of a LA ventilation system requires a dispersion system designed to mix the cryogenically produced cold air with the ambient warm air without creating plumes of very cold air. A simple system incorporating a booster fan to promote mixing was studied using a CFD model (Beiro-Romaro \& Cluff 2013).

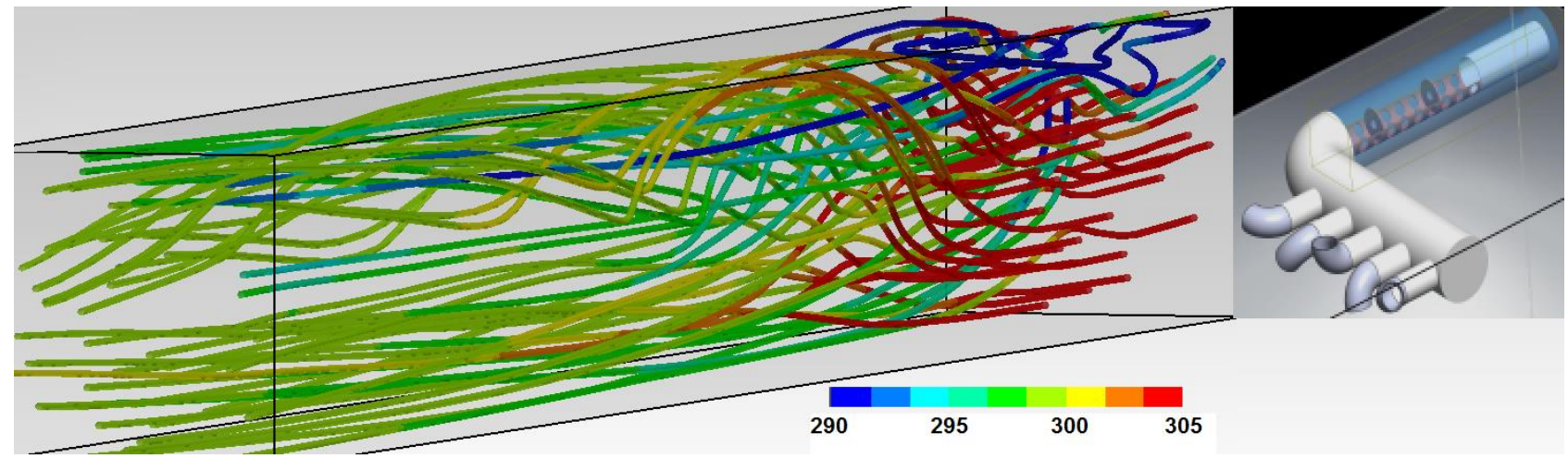

(a)

(b)

\section{Figure 7 Flow trajectories showing the mixing of LA ventilation (a); and the booster fan with associated dispersion system (b)}

The ambient temperature of the air entering the drift is $303 \mathrm{~K}\left(29.85^{\circ} \mathrm{C}\right)$ and the incoming air from the LA expansion is $100 \mathrm{~K}\left(-173.15^{\circ} \mathrm{C}\right)$. Clearly these cryogenic temperatures would be injurious should a worker be exposed to the raw output of the expanding LA; thus, a rapid mixing of the co-flows is required to avoid propagation of cold plumes. A booster fan dispersion system design, see Figure 7 (right) is located in the back of the drift and the output is represented by the blue flow trajectories in Figure 7 (left). The dimensions of the modelled drift in Figure 7 are $4 \times 4 \mathrm{~m}$ by $20 \mathrm{~m}$ long and the flow rate is $30 \mathrm{~m}^{3} / \mathrm{s}$. The simulated booster fan flow is $4 \mathrm{~m}^{3} / \mathrm{s}$ at ambient temperature and the liquid air flow is $1.2 \mathrm{~m}^{3} / \mathrm{s}$. The resulting average temperature is $299.28 \mathrm{~K}\left(26.13^{\circ} \mathrm{C}\right)$ a reduction of $3.72^{\circ} \mathrm{C}$ by the addition of $3.5 \%$ of the total air flow as LA after the initial expansion. This is a preliminary booster fan dispersion system design for the purpose of demonstrating the concept and requirement of co-flow mixing over a short linear extent.

\section{$5 \quad$ GoldFields South Deep Gold Mine}

The expansion of LA into a drift increases ventilation pressure and provides cooling of approximately $1 \mathrm{MW}$ for every $1.9 \mathrm{~m}^{3} / \mathrm{s}$ of LA ventilation. A good example for comparison is the GoldFields South Deep Gold Mine in South Africa. The anticipated water circulation for chilling is $1,200 \mathrm{l} / \mathrm{s}$ at $4^{\circ} \mathrm{C}$, produced by a combination of chillers and $100 \mathrm{~kg} / \mathrm{s}$ of ice conveyed from the surface. The $100 \mathrm{~kg} / \mathrm{s}$ of ice will be used to $\mathrm{cool} 500 \mathrm{l} / \mathrm{s}$ of the water to be available for fluctuations in demand (du Plessis et al. 2012). Assuming an initial temperature of $20^{\circ} \mathrm{C}$ the chilling of $700 \mathrm{l} / \mathrm{s}$ of water consumes $47 \mathrm{MW}$ and it takes $40 \mathrm{MW}$ to produce $100 \mathrm{~kg} / \mathrm{s}$ ice. Presumably, this energy will be absorbed by the ventilation air circulating throughout the mine, energy transfer rates depend on the temperature difference, turbulence and material properties amongst other factors. The expected total cooling required is $100 \mathrm{MW} ; 30 \mathrm{MW}$ produced on the surface, the planned initial cooling of $30 \mathrm{MW}$ is for pre-chilling of the ventilation air to offset the auto-compression. The $40 \mathrm{MW}$ is produced by the 94 Level underground refrigeration machines and $30 \mathrm{MW}$ is produced by an ice making plant located at Twin Shaft. 
Using the methods described in previous sections, the auto-compression is easily offset by a flow of $198 \mathrm{l} / \mathrm{s}$ of liquid air and the chilling underground can be achieved using insertion points throughout the mine workings. Clearly since the LA transforms to gaseous air, while absorbing energy, unlike the need to return the water to surface or an underground chiller the liquid air pumping is a one-way obligation. Further cost benefit analysis is desired, however, the energy required to circulate $1,200 \mathrm{l} / \mathrm{s}$ of water, produce $100 \mathrm{~kg} / \mathrm{s}$ of ice, transfer to underground and return the water to surface should not compare favourably to the production and pumping of LA to underground storage and it may be that the size of ventilation infrastructure is reduced.

\section{Compressed air and electrical supply from liquid air}

Compressed air is a standard feature of any underground operation; typically, the air is produced at surface and pumped underground. In one Sudbury mine, there are four large compressors on the surface to supply the entire mine. Since the availability of LA is proposed, it is certainly a candidate for producing compressed air for underground operations. The proposition is to store LA at underground locations so it is readily available for compressed air and electrical production.

The typical operating pressure is $100 \mathrm{psi}$ or $689.5 \mathrm{kPa}$ and the demand can be tailored to suit the circumstances at a given level or supply zone of several levels. A compressed air system would be comprised of a high-pressure storage tank with liquid air feed to a surge tank for expansion and pressure production by absorbing ambient heat at a rate of $1 \mathrm{MW}$ for every $7.3 \mathrm{~m}^{3} / \mathrm{s}$. The initial temperature of the LA is $78.65 \mathrm{~K}$ and for a projected final temperature of $293 \mathrm{~K}$, the expansion factor is 3.73 producing $2.648 \mathrm{~m}^{3} / \mathrm{L}$. A $5 \mathrm{~m}^{3}$ surge tank with $4.8 \mathrm{~L}$ liquid air expanded to a gas at $293 \mathrm{~K}$ will be at a pressure of $730.8 \mathrm{kPa}$ and sufficient to supply a larger compressed air storage tank, the typical $100 \mathrm{psi}$ air supply $(689.5 \mathrm{kPa})$. Depending on the demand for compressed air, the surge tank cycle would absorb about $2 \mathrm{MJ}$. If the flow was $2 \mathrm{~L} / \mathrm{s} \mathrm{LA}$, representing a flow of $5.3 \mathrm{~m}^{3} / \mathrm{s}$ the heat absorption rate would be $0.73 \mathrm{MW}$.

Electricity generation is already established at the $350 \mathrm{KW} / 2.5 \mathrm{MWh}$ pilot plant at Slough, UK and can be implemented at underground levels by using a modular production facility that can be redeployed. The method is similar to any other electrical production facility, the LA is expanded, cooling the ambient surroundings in the process, the expanding gas is forced through a turbine, which rotates the generator. A need for stability and control exists in a situation such as electricity production; thus, it may be necessary to create circulation loops drilled into the rock to guarantee the heat transfer in a stable situation for a secure supply.

\section{$7 \quad$ Dearman and Stirling engines}

The Dearman engine is in development at the time of writing, but rapid advancement is expected. Since the technology relies on mature engineering and the subject of significant development funding, it is expected that the development will be rapid. The design and build of a single piston test engine was completed in 2013, field-testing of a 30-50 KW engine is expected by the end of 2014 and low volume manufacture is planned for the second half of 2015. Ventilation system design requires the inclusion of flow to remove heat and diesel exhaust particulates - imagine the exact reverse, where the exhaust from a scoop or LHD is cool clean air. The engine absorbs approximately twice as much heat as shaft power generated so a $670 \mathrm{HP}$ engine would provide $1 \mathrm{MW}$ of cooling. Both the Dearman and Stirling engines are capable of providing stationary motive force, but the Stirling engine is substantially more mature and readily available from many distributors. The efficiency of the Stirling engine is substantially increased by having such a low temperature heat sink as LA and is improved further by proximity to higher temperature waste heat, which would be available from gas turbine engines operating on natural gas. Either engine would be ideal for pumping, conveyance, milling, and crushing or electricity generation. 


\section{Conclusions}

Concepts for the use of LA in mining and especially for deep mining operations have been presented. Including a liquid air plant on surface to provide an energy storage system will provide opportunity to arbitrage energy price fluctuations and when used in combination with renewable energy sources provides stability of energy supply during downtime of a wind turbine or solar supply system. Auto-compression can be offset by introducing LA to the flow at depth or along the length of the shaft with the added benefit of reduced airflow demand from the surface and an increase in ventilation pressure. Ventilation in workings can benefit from the use of LA to supply air to blind drifts or for cooling. Introduction of LA to a higher temperature drift will assist with rapid rock skin temperature conditioning, which will further assist with the implementation of ventilation on demand systems. Booster fans at depth would still be employed; however, smaller systems will produce the equivalent pressure increase of larger fans when working in tandem with liquid air and assist with the mixing of the LA with ambient air. The reduction in fan size reduces both the initial capital investment and the long-term power consumption expenditure for the fan and the heat dissipation cost of delivering ice or chilled water to the drift is eliminated.

Emerging technologies such as the Dearman engine and the use of mature technologies like Stirling engines are both amenable to the implementation of LA by replacing diesel engines, saving on fuel and heat dissipation, and both become more efficient if waste heat is available. Underground services can benefit from modular compressed air stations offsetting the pressure losses of long distance pumping and the leaks associated with long piping systems. Electricity generation is a well-developed technology, replacing high voltage trunk lines from the surface and step down transformers with modular liquid air electricity generation stations would reduce underground infrastructure.

Liquid air is a concept that when fully developed appears to have the potential to reduce energy costs for ventilation and cooling, compressed air, pumping and portions of hoisting, crushing, grinding and mining transportation energy consumption. The collective impact of these design parameters affect about $75 \%$ of the energy required to operate a mine. Further studies of the implementation of liquid air in mine design from a deep mining perspective are ongoing.

\section{References}

AngloGold 1999, 'Mine Energy Guidelines, Analysis of energy usage in future AngloGold mines', contract no. AG000216, CSIR Mining Technology, 2002, Mine Energy Guidelines, Guidelines for phase one of Deep Mine: 1997 - 2002, Deep Mine Collaborative Research Programme.

Beiro-Romero, M \& Cluff, DL 2013, 'Deep Mine Ventilation: Using Liquid Air as a Source of Ventilation', research thesis CSM 3357, University of Exeter, Exeter.

Bossard, FC 1993, 'Calculating underground mine air cooling requirements', in R Bhaskar (ed.), Proceedings of the 6th US Mine Ventilation Symposium, Society for Mining, Metallurgy and Exploration, Englewood.

Cluff, DL, Kennedy, GA \& Bennett, JG 2013, 'Capturing energy from ventilation air methane at operating coal mines', Proceedings of the 23rd World Mining Congress 2013, paper 582, http://www.cim.org/en/Publications-and-TechnicalResources/Publications/Proceedings/2013/8/23rd-World-Mining-Congress/WMCO-2013-08-582.aspx

Cluff, DL 2014, 'Concepts in Coalmine Ventilation and Development of the VamTurBurner for Extraction of Thermal Energy from Underground Ventilation Air Methane', PhD dissertation, University of Exeter, Camborne School of Mines, Exeter.

Department of Climate Change and Energy Efficiency 2010, Supplementary Discussion Paper on Compliance Obligations and Enforcement Measures for the Proposed National Legislation for Minimum Energy Performance Standards (MEPS) and Energy Labelling, Department of Climate Change and Energy Efficiency Report 2010/05, viewed 14 July 2014, http://www.energyrating.gov.au/wp-content/uploads/2011/02/201005-meps-supplementary-paper-compliance.pdf

Du Plessis, J, Butterworth, M \& McIntyre, R 2012, 'Ventilation and cooling strategy for a deep mechanised mine - South Deep in South Africa', ICMM Second Health and Safety Conference, Poster Session, International Council on Mining and Metals, https://www.icmm.com/document/4743

Hilt, D, Cauley, G, Barber, PF, Boston, WT, Fidrych, M, Jones, SR, Mansour, Y, McMaster, DM, Newman, WK \& Winter, TM 2004, 'Technical Analysis of the August 14, 2003, Blackout: What Happened, Why, and What Did We Learn?', report to the NERC Board of Trustees by the NERC Steering Group July 13, North American Electric Reliability Council, Princeton, http://www.nerc.com/docs/docs/blackout/NERC_Final_Blackout_Report_07_13_04.pdf

Mclvor, A 2010, 'Mining and Energy', Cleantech Magazine - Fuel Cell Special, Sept/Oct 2010, viewed 11 July 2014 , http://www.cleantechinvestor.com/portal/fuel-cells/6422-mining-and-energy.html 
Navarro-Torres, VF \& Singh, RN 2011, 'Thermal State and Human Comfort in Underground Mining', in MA dos Santos Bernardes (ed.), Developments in Heat Transfer, InTech Europe, Croatia.

Strahan, D (ed.) 2013, Liquid Air in the energy and transport systems: Opportunities for industry and innovation in the UK - Full Report, report no. 21, The Centre for Low Carbon Futures, http://www.liquidair.org.uk/files/full-report.pdf 
